\title{
ÍNDIOS URBANOS: A MIGRAÇÃO DO POVO PANKARARU PARA A CIDADE DE SÃO PAULO ASPECTOS TERRITORIAIS E IDENTITÁRIOS
}

\author{
Evanio Santos Branquinho ${ }^{1}$ \\ Ângelo José de Oliveira Júnior²
}

\begin{abstract}
Resumo: O povo Pankararu é uma etnia indígena que tem sua origem no sertão de Pernambuco e há décadas estabeleceu uma rota migratória para a cidade de São Paulo, em especial para a favela do Real Parque, localizada no distrito do Morumbi. Devido à escassez de recursos, problemas fundiários e adversidades climáticas, uma parcela da população migra para São Paulo em busca de melhores condições de subsistência e tenta se estabelecer no local onde já existe um grupo dessa etnia. $A$ presente pesquisa possui abordagem qualitativa e tem como objetivo compreender as relações estabelecidas no processo migratório do povo indígena Pankararu e questões territoriais, culturais, sociais e históricas decorrentes deste processo, do interior de Pernambuco para a cidade de São Paulo. Através de entrevistas semiestruturadas, realizadas com os indígenas moradores do Real Parque, pôde-se perceber o contraste social entre a favela do Real Parque e o bairro de mesmo nome e o Morumbi.
\end{abstract}

Palavras-chave: Pankararu, território, migração, identidade, cultura.

\section{URBAN INDIANS: THE MIGRATION OF THE PANKARARU PEOPLE TO THE CITY OF SÃO PAULO TERRITORIAL AND IDENTITY ASPECTS}

Abstract: The Pankararu people are an indigenous ethnic group that has its origin in the backlands of Pernambuco and for decades has been establishing a migratory route to the city of São Paulo, especially to the Real Parque slum, located in the district of Morumbi. Due to the scarcity of resources, land problems and climatic adversities, a portion of the population migrates to São Paulo in search of better subsistence conditions and tries to establish themselves in the place where a group of your ethnicity already exists. The present study has a qualitative approach, and aimed to understand the relations established in the migratory process of the Pankararu indigenous people and territorial, cultural, social and historical issues arising from this process, from the state of Pernambuco to the city of São Paulo. Through semi-structured interviews, conducted with the indigenous residents of Real Parque, it was possible to perceive

\footnotetext{
${ }^{1}$ Professor do curso de Geografia da Universidade Federal de Alfenas (UNIFAL). Email: esbranquinho@uol.com.br

${ }^{2}$ Licenciado em Geografia pela Universidade Federal de Alfenas (UNIFAL). Email: angellojunior@ hotmail.com
} 
he social contrast between of the Real Parque slum and the neighborhood of the same name and Morumbi.

Keywords: Pankararu, territory, migration, identity, culture.

\section{INTRODUÇÃO}

Considerando o território nacional, os índios da região Nordeste são os mais vitimados diante dos intensos embates entre indígenas e posseiros durante a história Além de sofrerem com as condições naturais, tais como a seca, os conflitos fundiários são fortes propulsores para as migrações.

Nesse contexto de migração de povos indígenas para as áreas urbanas, a zona sul da cidade de São Paulo, mais precisamente, no Real Parque, tem uma concentração considerável de índios pertencentes à tribo Pankararu. A favela Real Parque $^{3}$, localizada no bairro de mesmo nome no distrito do Morumbi $^{4}$, situa-se às margens do Rio Pinheiros (Figura 1), onde se formou em meados da década de 1960, e conta atualmente com aproximadamente 5.300 habitantes, em sua maioria migrantes nordestinos que vieram em busca de melhores condições de vida na metrópole (MARTINS, 2014).

Figura 1. Localização e delimitação da área da Favela Real Parque

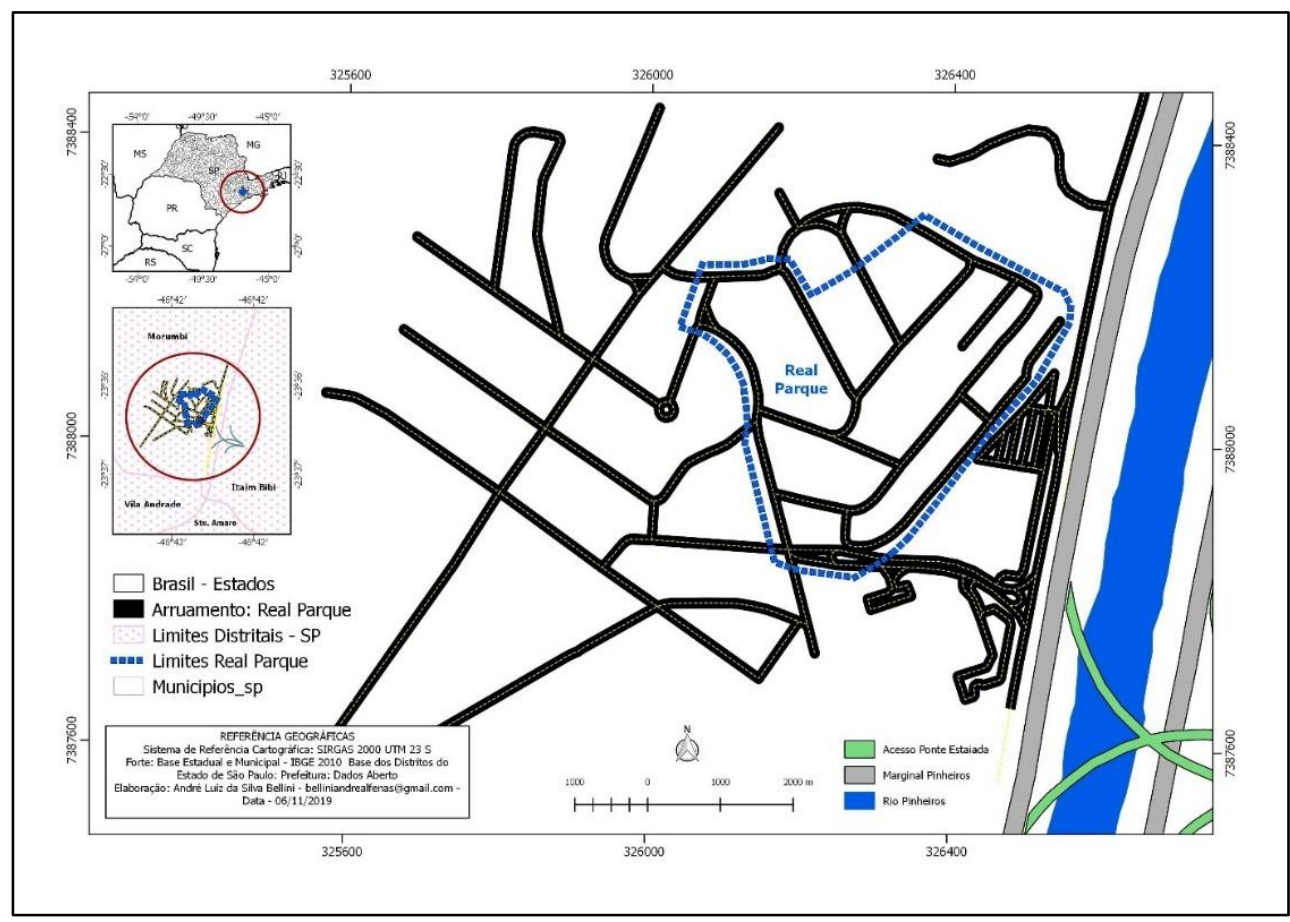

Fonte: IBGE, 2010.Organizado pelos autores (2019) e elaborado por André Luiz da Silva Bellini, 2019

\footnotetext{
${ }^{3}$ Optou-se em manter a denominação "favela do Real Parque", apesar das obras de urbanização e regularização fundiária que ocorreram, em função da precariedade de acesso aos serviços públicos e da discriminação que este local e seus moradores sofrem. O termo "comunidade", em substituição à favela, poderia encobrir muitas das relações discriminatórias dentro da própria favela em relação aos indígenas, e desta em relação aos bairros do Real Parque e do Morumbi. Neste trabalho, o termo comunidade aparece apenas em relação ao grupo étnico Pankararu.

${ }^{4} \mathrm{O}$ crescimento do bairro do Morumbi e adjacências resulta na formação do distrito do Morumbi, composto atualmente por 19 bairros, inclusive os bairros do Morumbi e Real Parque. Faremos referência aqui tanto ao bairro quanto ao distrito do Morumbi. Este último também denominaremos como região do Morumbi.
} 
O presente estudo tem como objetivo principal compreender as relações estabelecidas no processo migratório do povo indígena Pankararu e as questões territoriais, culturais, sociais e históricas decorrentes deste processo, do sertão de Pernambuco para a cidade de São Paulo.

Como objetivos específicos, busca-se entender as territorialidades do grupo quanto ao processo de desterritorialização e reterritorialização bem como compreender as identidades culturais e territoriais dos indígenas moradores da favela Real Parque, no que concerne ao seu modo de vida e inserção no local.

\section{PROCEDIMENTOS METODOLÓGICOS}

Inicialmente, foi realizado levantamento bibliográfico sobre questões relacionadas ao histórico dos povos indígenas no Brasil e sobre os índios que migram para as cidades em busca de melhores condições de vida, considerando os conceitos acerca de território, identidade e cultura. Também foi revisado o histórico da tribo Pankararu, de sua origem no estado de Pernambuco aos caminhos que trouxeram parte dessa etnia ao Sudeste, em especial para a cidade de São Paulo.

Um roteiro semiestruturado de entrevista foi elaborado, contendo questões norteadoras relacionadas ao território, identidade, cidade, preconceito, entre outros, com a proposição de novas questões durante os diálogos e ao contexto colocado.

Em relação à cultura, assume importância não apenas a questão da identidade em si, mas as interações entre os diversos agrupamentos sociais, pois são estas que constituem os contextos de relações e transformações desses grupos.

No presente estudo, foram entrevistados três moradores da comunidade no Real Parque, número esse que foi determinado pela liderança da Associação Indígena, representante dos Pankararu no local. Todos possuem em comum o fato de terem vindo de Pernambuco para São Paulo, embora por motivos diversos.

\section{O POVO PANKARARU: ORIGEM E LOCALIZAÇÃO}

De acordo com Nakashima (2009), o povo Pankararu é uma das etnias pertencentes ao estado de Pernambuco e seus remanescentes encontram-se situados nas cercanias do Rio São Francisco, abrangendo os municípios de Petrolândia, Tacaratu e Jatobá.

Seu território abrange hoje 15.297 hectares, divididos entre a denominada Terra Indígena Pankararu, compreendendo uma região de 8.377 hectares, demarcada em 1940 pelo Serviço de Proteção ao Índio (SPI) e homologada pelo governo brasileiro em 1987, e a Terra Indígena Entre Serras, homologada em 2006 e com um território de 7.150 hectares. Juntas as terras agregam 15 aldeias: Brejo dos Padres, Caldeirão, Espinheiro, Carrapateira, Barrução, Saco de Barros, Olaria, Cacheados, Logradouro, Tapera, Agreste, Macaco, Barriguda, Saco de Porcão e Bem Querer (MAURO, 2007).

Dentre as citadas aldeias, o Brejo dos Padres foi o aldeamento resultante da junção de diferentes etnias, dentre elas os Pankararu. Provavelmente, por volta de 1802, missionários oratorianos ou capuchinhos deram início a esse aldeamento que sobreviveu até 1875, quando foi extinto por fazendeiros locais que reclamavam as terras. Na visão dos aldeados, as famílias foram expulsas e se espalharam, e os invasores se estabeleceram no local por meio da demarcação de lotes de terra (NAKASHIMA, 2009). 
Somente a partir da década de 1930 , sob protestos dos moradores do local, foi conquistado o direito de instalação de uma sede do SPI. Enquanto, o processo de demarcação de suas terras somente foi reconhecido em 1987, quando uma primeira parte do território Pankararu foi homologada pelo governo federal (SILVA, 2006).

\section{ÍNDIOS URBANOS: A MIGRAÇÃO DO POVO PANKARARU PARA A CIDADE DE SÃO PAULO}

Índios urbanos, índios na cidade, índios citadinos, índios em área urbana e índios em contexto urbano. Ainda não há consenso sobre a terminologia nas pesquisas, visto que o estudo da temática é incipiente. Também é desafiador, pois abordar a realidade indígena em um contexto urbano constitui uma análise complexa e muito dinâmica (NASCIMENTO; VIEIRA, 2015).

Compreender o modo de vida e as percepções dessas pessoas no contexto urbano, assim como a trajetória dessas até os centros urbanos assume uma grande importância. São inúmeras as variáveis a considerar na apreensão da vivência dos povos indígenas nas cidades, em especial nas áreas metropolitanas, como no caso de São Paulo. Nakashima e Albuquerque (2011) salientam que:

A presença de indígenas nas grandes cidades é resultado dos processos de deslocamento dessas populações de suas terras tradicionais para os centros urbanos, que são, em geral, os polos históricos de migração do país, como é o caso da cidade de São Paulo (NAKASHIMA; ALBUQUERQUE, 2011, p.183).

Os autores referidos afirmam que os principais fatores para o aumento da população urbana indígena podem ser entendidos sob três óticas: primeira, relacionada ao próprio crescimento vegetativo dessa população em áreas urbanas; depois, em função de que as migrações ocorrem, em primeira instância, para os centros urbanos do próprio estado, o que implica na urbanização de áreas antes consideradas rurais; e por fim, e talvez a mais importante, é a auto-declaração de pessoas que antes por motivos diversos não se declaravam como indígenas e hoje o fazem para garantir seus direitos e fixar sua identidade étnica e cultural.

De toda forma, esse fenômeno sempre estará relacionado ao contato com populações não indígenas e não raramente à violência infligida pela expulsão das terras tradicionais. No entanto, também deve levar-se em conta as motivações dos próprios indígenas para suas migrações, tais como a busca por melhores condições de vida. O fato é que, independentemente da forma, essas migrações estão relacionadas à falta de opções, saindo de seus locais de origem à procura de emprego, saúde e educação (MARTINS, 2014).

Por esse fato é que, a partir da década de 1940, houve uma intensificação de migrantes do Nordeste para as grandes cidades do Sudeste. Inicialmente, com o intuito de complementar a renda familiar, os homens vinham por serviços temporários e, passados os períodos de seca e estiagem, retornavam ao seu local de origem. Entretanto, com o passar dos anos, as mulheres começaram a percorrer o mesmo caminho e também a permanecer um maior período. Isso contribuiu para a vinda dos mais jovens, através da criação de vínculos e apoio dos que já estavam estabelecidos no centro urbano. O processo de reterritorialização do grupo se deu em parte em função dessa rede criada, tanto de forma política quanto social, fortalecendo esse movimento migratório (ARRUTI, 1999). 
Como comenta uma das entrevistadas:

Na verdade eu fui trazida de lá pra cá né, na época eu só tinha 15 anos e morava com a minha vó, minha mãe foi a primeira a vim pra cá, ela veio pra trabalhar, mãe solteira 4 filhos, então ela veio pra trabalhar e depois de 4 anos minha vó faleceu e minha tia adoeceu também e ela acabou trazendo todo mundo pra cá, então eu não tinha alternativa né, eu tinha que vim de qualquer jeito com 15 anos não tem como a pessoa decidir que quer ficar (Clarice Pankararu).

De acordo com Brito (2000), as migrações não são fenômenos exclusivamente demográficos, como também não são consequências de decisões individuais. As migrações não acontecem de forma isolada, mas sim de forma coletiva, que carregam seus valores e normas, e esse fenômeno ocorre entre cidades, estados, países ou simplesmente de um espaço rural para o urbano, e é sustentado pelo desenvolvimento desigual do capitalismo, causando grandes disparidades regionais.

Dados do Censo 2010 demonstram que o número de indígenas vivendo em São Paulo somava aproximadamente 63.789 indivíduos, sendo o terceiro estado brasileiro em número de indígenas. Desse total, 58.842 deles viviam em áreas urbanas e destes, 33.829 eram habitantes da região metropolitana.

Os Pankararu estão nesse processo migratório há muitos anos, em busca por trabalho e melhores condições de vida. A própria escassez de terras, devido a problemas fundiários, à falta de recursos e a fatores climáticos, como referido, estão entre os principais motivos que contribuem para esse fenômeno. A etnia estudada aqui soma, na cidade de São Paulo, uma parte de sua população de origem em busca de melhores oportunidades. Segundo um desses migrados:

Nóis vive lá de plantação quando chove, e quando Deus não manda chuva, a maioria dos índios vaga no mundo, mas nosso lugar se fosse muito "chovedor" e tivesse muito emprego, não tinha lugar melhor que o nosso não, então foi por causa da seca (Adilson Pankararu).

Conforme os relatos, a seca e a falta de trabalho acabam sendo os principais causadores das migrações para as cidades; entretanto, segundo eles, uma parte dos indígenas, principalmente os mais jovens, vão pra cidade para estudar pois na aldeia o estudo é limitado:

[...].eles vindo pra cá e estudando, principalmente agora, como teve uma retomada de terra lá e tudo, então que dizer a aldeia querendo ou não aumentou, então vai ter mais escolas, mais atendimento, então o pessoal quando vem pra cá sempre procura estudar pedagogia, na área da saúde, porque eles sabem que quando voltar pra lá vão ter o retorno, eles vão poder atuar lá, essa questão de que não é todo mundo que pode estudar, que o indígena não pode estudar é colocada pelo branco(Clarice Pankararu).

Portanto, depois de concluído os estudos, muitos acabam voltando para a aldeia para aplicar os conhecimentos adquiridos e assim poderem minimizar as necessidades dessa população.

Isso demonstra o quanto as migrações tornam-se fatores importantes para o desenvolvimento das sociedades, que são transformadas de acordo com as interações e as necessidades tanto nos locais de destino quanto nos locais de origem no sentido econômico, social, político e cultural. 
Nos locais de destino, pode-se afirmar que o contingente de indígenas Pankararu, a partir da década de 1950, foi absorvido especialmente na construção civil, como nas obras do estádio do Morumbi e do palácio dos Bandeirantes, nova sede do governo do Estado. A localização dessas edificações, dentre outros fatores, explica o fato dos Pankararu terem se estabelecido onde hoje vivem, ou parte deles, no Real Parque (MARTINS, 2014), conforme discutiremos mais à frente.

A ocupação dos Pankararu em São Paulo articula-se ao movimento de expansão urbana da região sudoeste da cidade. Os bairros além Rio Pinheiros formaram-se no processo de desconcentração de atividades, equipamentos e população da área central, para o qual o afluxo de mão de obra numerosa e barata foi fundamental na reprodução do espaço metropolitano.

Em estudo realizado por Arruti (1999), estimava-se que os Pankararu residentes no Real Parque somavam em torno de 1500 pessoas. Entretanto, segundo a presidente da Associação Indígena SOS Pankararu, que atua no local, esse número varia muito, em função das condições de precariedade do grupo:

São 170 famílias, que dá umas 700 pessoas mais ou menos, só aqui, mas varia muito também, porque eles mudam bastante, tem aqui, no Panorama, Paraisópolis, como muitos moram de aluguel então uma hora estão aqui outra hora não estão mais. Mas o primeiro lugar que eles vêm quando chegam é aqui no Real Parque, pelo motivo de ter mais parente, mas depois quando começam andar com as próprias pernas, já tem um emprego ou estão estudando, eles não ficam só aqui no Real Parque não (Clarisse Pankararu).

Esses números se referem às famílias cadastradas na Associação SOS Pankararu. Essa organização não governamental, criada em 1994, serve como resgate e apoio aos indígenas na manutenção de seu vínculo com a etnia. No decorrer da década de 1990, através da visibilidade conseguida nos meios de comunicação, o grupo pleiteou sua condição na cidade de São Paulo enquanto aldeia, não se desligando de sua origem em Pernambuco. Através de ações da ONG e com apoio municipal, foi criada em 2003 a "Ação Cultural Indígena Pankararu", cujo objetivo é resgatar os costumes e práticas culturais do povo, para que o mesmo não perca sua identidade com o tempo e com o novo tipo de território (MARTINS, 2014).

\section{DES-RE-TERRITORIALIZAÇÃO, CULTURA E IDENTIDADE PANKARARU NA CIDADE DE SÃO PAULO}

Os indígenas que residem na favela do Real Parque ocupam um território que não é exclusivo deles e o que se observa no local é uma grande heterogeneidade, característica da complexidade de uma metrópole. Nesse aspecto, mostram-se em um contínuo processo de adaptação com o espaço urbano no qual ocupam, que implica uma necessidade constante de afirmação tanto territorial, quanto identitária.

Haesbaert (2005) afirma que o conceito de território está intrinsecamente relacionado a duas características: a funcional, estabelecida por relações de posse, propriedade e dominação, entendido como um espaço que manifesta as relações de poder estatal e econômico, onde se observa a des-re-territorialização como consequência das disputas das classes sociais que ocorrem na relação capital/trabalho; e a simbólica, também chamada de cultural, que remete à produção 
de significados, cuja ramificação com o território é estabelecida pela relação de apropriação e pertencimento, através do imaginário, do uso e do vivido.

De acordo com Souza (2015), o poder é exercido através e com referência a um território. Os limites espaciais, mesmo que pouco definidos, são aqueles que concretizam o poder. Em nenhuma situação este será exercido sobre um grupo sem que estejam inseridos e em conexão com um espaço. Assim, o uso por meio das práticas espaciais, tais como as condições de acesso e locomoção, modificação e ressignificação de espaços, definição de novas fronteiras, são objetos da instrumentalização e alteração do território.

Dessa forma, o território antes de mais nada está intrinsecamente relacionado com as relações de poder estabelecidas com o espaço. Quando se trata de populações indígenas, o que se destaca é que essas populações estabelecem uma relação de pertencimento com algum espaço onde não deixam somente suas marcas fisicamente como também espiritualmente. Portanto, o estudo do território dessas populações pode ser abordado do ponto de vista físico e simbólico.

Quando ocorre a mudança ou a perda desse domínio em determinado território ocorre o processo de desterritorialização, definido quando um sujeito ou um grupo perde ou deixa de desempenhar relações de poder em um determinado território. Quando passa a exercer relações de poder e ocupação em outro local, inicia-se um processo construtivo no qual passa a desempenhar domínio sobre outros espaços, sejam eles materiais, simbólicos ou culturais, esse processo é denominado de reterritorialização (HAESBAERT, 2011).

De acordo com Saquet e Mondardo (2008), são nos processos de desterritorialização que o migrante carrega diferentes possibilidades de reconstrução do seu espaço, ou seja, da sua reterritorialização. Isso inclui ainda a relação mantida com o ponto de origem, através de relações sociais. Esse vínculo com sua origem é apontado por dois dos entrevistados:

Então, eu sempre volto né, tenho um irmão lá, tenho meus tios por parte de pai, tenho meus tios também por parte de mãe, meu avô mora lá, então eu tenho muito parente lá, sempre que eu vou, eu vou na casa de cada um ou pelo menos em alguns, eles moram tudo na aldeia, minha sogra mora lá também, meu marido é indígena também (Clarice Pankararu).

Sim tenho bastante parente lá, mas aqui também tem bastante parente, mas de vez em quando nóis vai pra lá, em época de festa, ou então só pra passear mesmo (Adilson Pankararu).

Os povos indígenas carregam uma multiplicidade cultural ampla e distinta, fazendo com que se estabeleça uma significativa relação espiritual com a terra. Como explica Haesbaert (2005), a força da identidade é um dos principais fatores de união entre os grupos mesmo estando distante de seu território original, fazendo com que os mesmos adaptem seus costumes no novo território, materializando assim o processo de reterritorialização.

Haesbaert (2004) também define desterritorialização como sendo uma forma de exclusão e degradação do território, cujo processo se dá devido ao domínio do capitalismo, no qual acaba acentuando as desigualdades, culminando na precarização dos menos favorecidos economicamente, essa definição pode ser nitidamente observada na favela visitada durante o trabalho de campo, pois de um lado se observa a carência do lugar, que há pouco tempo vem passando por uma 
reurbanização, e de outro percebe-se os bairros do Real Parque e do Morumbi, que são formados por moradores de classe média alta da cidade de São Paulo (Figura 2).

Figura 2. Vista panorâmica da Favela Real Parque e edifícios no Morumbi

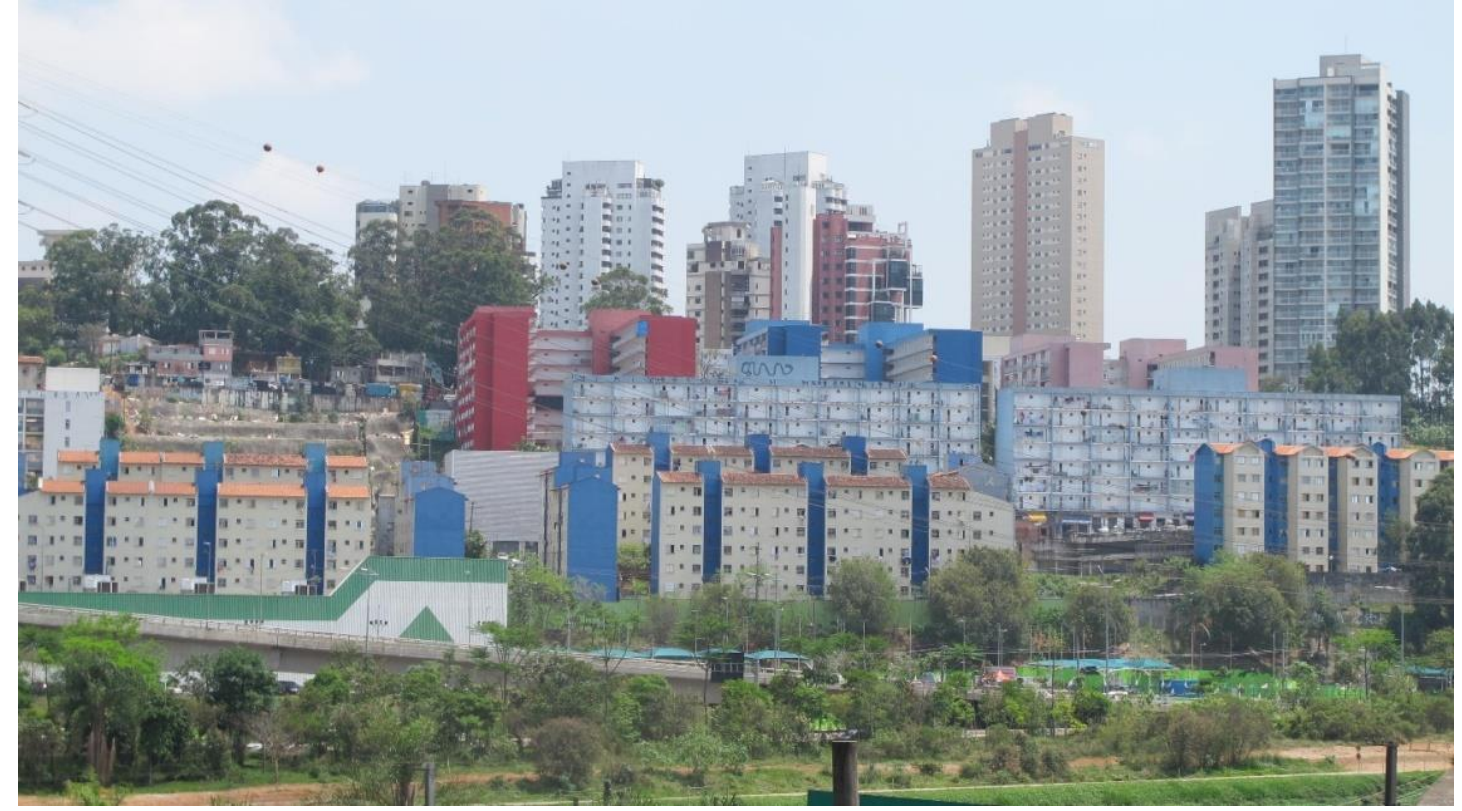

Fonte: autores, 2019

Esses elementos são evidenciados na fala de uma das entrevistadas, afirmando as dificuldades de inserção e adaptação a esse novo território:

A gente veio por uma precisão, uma necessidade e acaba se acostumando com tudo né, com as coisas ruim, com as coisas boas também, dá pra acostumar, eu acho que eu só tô aqui porque eu me acostumei mesmo, por tudo que eu passei, mas não assim, ai minha aldeia eu trocaria porque eu já me acostumei, aqui está sendo melhor, não, não é que está sendo bem aquele melhor, porque se não fosse o meu trabalho jamais eu estaria aqui, porque o melhor é isso, é você ter o seu trabalho, se você não tiver, jamais. E agora com esses "predinhos" se você não tem dinheiro pra pagar o que você deve então você não está no melhor mesmo (Lídia Pankararu).

A existência de diversos e intensos processos de reclusão identificados atualmente evidenciam a complexidade do território nessa dinâmica. De forma paralela, dialeticamente ao que pode ser concebido como "capitalismo pós-fordista", flexível e móvel em sua capacidade de processos excludentes (HAESBAERT, 2004).

$O$ autor complementa que, apesar da fragilidade $e$ fluidez desterritorializadora nos aglomerados de exclusão, pode ocorrer o seu contrário, de modo dialético: situações de territorializações extremamente precárias levam à fixação restrita e fechada radicalmente de determinado território, que não obrigatoriamente leva a uma menor precariedade, já que podemos ter a desterritorialização in situ; segundo este autor: "A precarização social mais desterritorializadora pode alimentar a mais excludente das territorializações, assim como a mais fechada e excludente territorialização pode provocar ou mesmo significar em si mesma a mais radical desterritorialização" (HAESBAERT, 2004, p. 38).

Cabe ressaltar acerca do estabelecimento dos Pankararu nessa região, diversas esferas devem ser consideradas, sejam elas políticas, sociais ou culturais. 
Pois tais esferas atuam nas condições de acessibilidade aos direitos urbanos, como no caso dos Pankararu, a favelização é um indicador da carência desses direitos.

O que de maneira bastante real os afasta de alcançar a sua plena cidadania indígena, estando eles imersos em um Estado Democrático de Direito com tendências liberais e universalizantes, quando se trata dos processos de afirmação das identidades em suas relações com as dinâmicas econômicas e políticas no atual mundo globalizado (MARTINS, 2014, p.113).

A favela do Real Parque é constituída em grande parte por moradores não indígenas, e assim como inúmeras localidades periféricas, sofrem com as ações dos poderes estabelecidos nesses territórios, como os do tráfico de drogas. Porém, como explica uma das entrevistadas, a comunidade, com o passar do tempo, foi conquistando espaço e direitos aos integrantes da etnia, o local vem passando por um processo de melhorias urbanísticas, como de relocação de moradores que habitavam em barracos e atualmente residem em apartamentos do conjunto habitacional, que foram sendo construídos no próprio local. Como comentou Clarice durante a entrevista:

[...] eles vieram pra cá pra urbanizar e quando eu cheguei aqui já ouvia falar dessa urbanização, então a gente já estava aqui, e eles tiveram que fazer o cadastro de todo mundo, pois eles não iam saber quem era Pankararu e quem não era, então eles tiveram que fazer o cadastro normal de todo mundo, então se você tinha seu barraco você tinha direito, eles iam construindo e já colocava as famílias nos apartamento, não teve muita espera, no caso desses aqui, foi quando teve um incêndio, e deixou muita gente desabrigada, ai eles fizeram os primeiros apartamentos aqui do lado, ai teve o cadastro do auxílio aluguel, à medida que foi ficando pronto já foram trazendo as famílias (Clarice Pankararu).

Conforme Barbosa e Silva (2013), a cidade é resultado de uma construção coletiva que envolve diferentes experiências e concepções de mundo, é resultado da união das relações sociais e da natureza, sendo o espaço no qual se sobressaem as diferenças. É no espaço urbano onde ocorrem as mais diversas formas de produção de territórios sejam eles contínuos ou descontínuos.

Esses diferentes territórios contribuem na reprodução de segmentos de diferentes classes sociais, as camadas mais ricas vão ocupar as áreas mais privilegiadas, onde existe uma melhor infraestrutura, e a mais carente e de baixo poder aquisitivo vai ocupando as áreas mais precárias desse espaço, onde surgem aglomerados conhecidos popularmente como favelas ${ }^{5}$.

\footnotetext{
${ }^{5}$ De acordo com o IBGE (2019), o termo "Favela" é denominado como "Aglomerado Subnormal", definido por uma forma irregular de ocupação de terrenos de propriedade alheia ou públicos, suas características principais são o crescimento de padrões urbanísticos irregulares e deficiência de serviços públicos essenciais.
} 


\section{A PRODUÇÃO DO ESPAÇO METROPOLITANO E A SEGREGAÇÃO DOS PANKARARU}

É importante situar a ocupação dos Pankararu em São Paulo no processo de metropolização ${ }^{6}$, quando se intensificam, segundo Langenbuch (1968), a compactação da área edificada da cidade, especialmente no centro e bairros próximos, e a expansão da área edificada sobre os arredores significativamente suburbanizados ou não, os quais foram marcados por intensa segregação social. Os Pankararu são representativos desse processo, e é nesse contexto que eles buscaram sua inserção e apropriação de um novo território.

Faria (2015) expõe como o aprofundamento das relações capitalistas, verificado na produção da metrópole paulista na primeira metade do século $\mathrm{XX}$, através de grandes obras de infraestrutura, a exemplo da instalação de represas, rodovias e linhas de transmissão, assim como a periferização, expropriou o território indígena Guarani ali existente, apropriando-se do território e mobilizando a terra como mercadoria.

A autora cita o exemplo da construção da represa Billings que modificou os espaços de deslocamentos dos índios Guarani e os seus significados, os quais não perderam apenas a terra, alagada pela represa, mas a alimentação com o fim da pesca devido à poluição das águas, expropriando-os e confinando-os em um território com fronteiras delimitadas do parque Jaraguá, retirando suas práticas e mobilidade, afetando gravemente sua identidade (FARIA, 2015).

$\mathrm{Na}$ região sudoeste da cidade de São Paulo, fazem parte do processo de estruturação do espaço metropolitano, a drenagem da várzea e a canalização do Rio Pinheiros, construindo as avenidas marginais, as quais aumentaram a acessibilidade, e produziram a valorização do espaço, em função dos loteamentos dos terrenos conquistados à várzea, esta que constituía um "limite rígido" à expansão urbana (AB'SABER, 2007, p. 162 e 178).

Os bairros além-Pinheiros, na porção sudoeste da cidade, formaram-se, portanto, no contexto de metropolização, até então essa região era constituída predominantemente de sítios, fazendas e chácaras. Em 1957, Ab'Saber salientava sobre a expansão dessa área e o seu padrão de ocupação:

Alguns baixos terraços mais enxutos foram o sítio preferido dos bairros dessa parte da cidade; com a retificação do Pinheiros esboça-se uma extensão dos mesmos e a consequente conquista do solo das várzeas. Após o canal do Pinheiros estende-se uma das mais extensas áreas de loteamentos aristocráticos atuais da cidade de São Paulo, representadas pelos bairros-jardins Morumbi, Leonor, Guedala, e Cidade Jardim (AB'SABER, 2007, p. 176).

As obras de grande porte, do estádio do Morumbi ao final da década de 1950, e depois o Palácio dos Bandeirantes, como referido anteriormente, geraram uma demanda de mão de obra suprida por trabalhadores migrantes que foram se estabelecendo em habitações precárias nos arredores, em glebas vazias com maiores declividades e fundos de vale. Os Pankararu, vindos para trabalhar nessas e outras obras, ocuparam terrenos próximos ao Rio Pinheiros, e junto a outros trabalhadores

\footnotetext{
${ }^{6}$ Langenbuch (1968) situa o período de 1915-1940 como o de início da metropolização da Grande São Paulo, e o período a partir de 1940, como a grande metropolização recente
} 
não indígenas, formaram em 1956, uma ocupação, denominada favela da Mandioca, que posteriormente constituiria a favela do Real Parque.

Assim, por volta de 1975 a 1985 a necessidade de mão de obra nas edificações que estavam sendo construídas e o impulso imobiliário, foram os principais motivos para o crescimento da localidade. Na década de 1980, a população da favela triplicou a qual boa parte se insere na área de serviços desqualificados. À medida que a área ocupada foi avançando, incorporava-se ao bairro Real Parque, tanto no âmbito geográfico quanto no econômico, mas de forma precária, visto que os moradores da favela sem muitas opções de emprego, acabavam servindo ao mercado de trabalho informal, dependente das ofertas de trabalho oferecidas nas adjacências (D'ANDREA, 2008).

No contexto da região do Morumbi, Gohn (2010) apresenta uma síntese das transformações urbanas verificadas: nos anos 1970, intensificou-se o crescimento do setor sudoeste da cidade, com o boom da construção civil, quando novos loteamentos são abertos, e na década de 1980, avança o processo de verticalização na região. A partir dos anos 2000, condomínios horizontais de alto padrão passam a ser construídos em terrenos de antigos casarões. Simultaneamente a esse movimento, ocorre a expansão e o crescimento de suas favelas, em especial a do Paraisópolis, que é a segunda maior favela da cidade, consolidando a composição social mista da região, marcada pelos altos níveis de desigualdade e segregação.

A partir do final dos anos 1990, a favela do Real Parque passou por série de intervenções urbanísticas, como o projeto Cingapura em 1996, construção de prédios populares, que atende uma pequena parcela dos moradores, uma vez que ele foi edificado apenas nos terrenos frontais da favela na Marginal do Pinheiros. Em 2008, os terrenos com riscos geológicos são recuperados e construídos conjuntos habitacionais populares (PRADO, 2017) (Figura 2).

De acordo com Rezende (2015), a favela do Real Parque possui um diferencial quando comparada a outras favelas existentes na cidade de São Paulo, pois ao invés de se localizar em regiões periféricas menos valorizadas, ela se localiza em uma parte nobre da cidade, dividindo o território entre conjuntos habitacionais e edifícios de alto padrão, e em frente ao centro empresarial e financeiro da Avenida Berrini e da Marginal Pinheiros

A construção do Shopping Cidade Jardim em 2006, um conjunto de torres de apartamentos, escritórios e shopping center de elevado padrão, removendo parte da favela Jardim Panorama, vizinha ao Real Parque na Marginal Pinheiros, acentuou ainda mais os contrastes socioeconômico e os níveis de segregação na região, com a formação do que Caldeira (2000, p. 254, 255) denomina de "enclaves fortificados", onde: "Diferentes classes sociais vivem mais próximas umas das outras em algumas áreas, mas são mantidas separadas por barreiras físicas e sistemas de identificação e controle".

\section{CULTURA COMO FORMA DE RESISTÊNCIA E IDENTIDADE}

O povo Pankararu, assim como outras etnias indígenas, possui uma vasta rede de significações culturais e religiosas. Atualmente uma parcela vive nas cidades, onde recorre aos rituais e crenças para manter viva a sua cultura e também como forma de marcar sua resistência no local.

Os residentes indígenas na favela do Real Parque realizam anualmente seus rituais religiosos na quadra de uma escola localizada no bairro. Nesse local, acontece seu mais importante ritual, denominado Dança dos Praiás (Figura 3). 
Figura 3. Manifestação da Dança dos Praiá em quadra da escola no Real

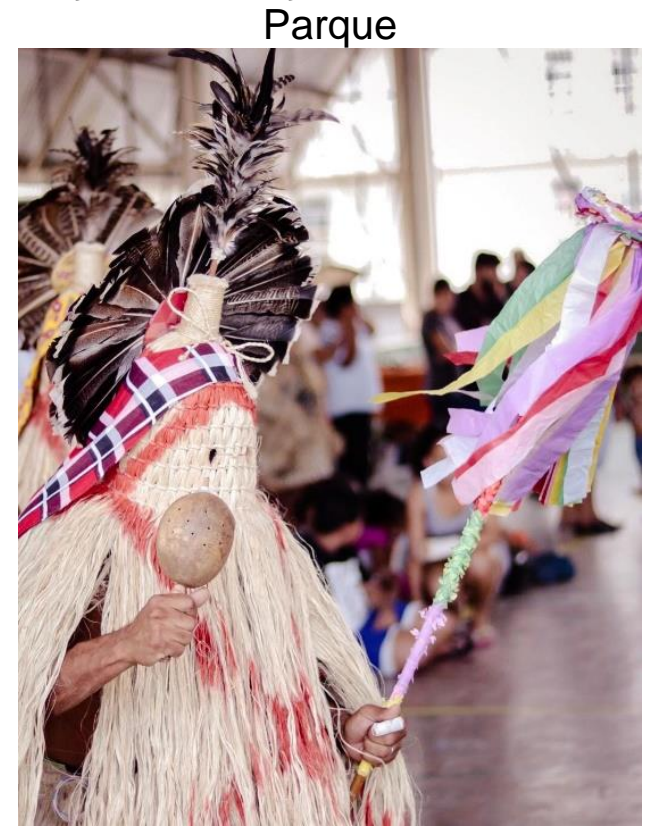

Fonte: Associação Indígena SOS Pankararu, 2019

Tais rituais devem ser realizados regularmente e em locais reservados, pois de acordo com os entrevistados, não existe uma boa aceitação por parte dos moradores não indígenas. Como salienta Claval (2014), a cultura não é vivenciada de forma passiva pelos que a recebem, estes reagem ao que lhes é imposto, interiorizando ou rejeitando traços. Ao longo da vida criam maneiras de fazer, moldam seus sonhos e pesadelos e criticam valores habituais que não correspondem às suas expectativas.

Conforme Albuquerque (2009), a Dança dos Praiás, quando apresentada publicamente pelos moradores da comunidade no Real Parque, mesmo como um modo de expressão cultural, provoca problemas quanto à sua legitimação, pois o ritual atua como forma de reivindicação de sua identidade indígena, dado que essa manifestação ficou por muito tempo restrita à aldeia em Pernambuco. Como salienta uma das entrevistadas:

[...] se a gente querer ser indígena aqui nesse território né, porque se a gente for fazer o nosso ritual, se a gente for manter a nossa cultura aqui, eu acho que não existe esse respeito por parte das pessoas aqui, porque incomoda o povo né, tudo incomoda ou porque você quer ser o "indinho", e então lugar de índio é lá na mata, lá no mato, é lá na sua aldeia, não é aqui na cidade, pra você querer tá fazendo isso ou fazendo aquilo, então existe essas críticas e não mudou nada até hoje (Ligia Pankararu).

Todos os domínios de uma sociedade têm a influência da cultura. O modo como é percebido o mundo, o ambiente e a sociedade, o valor que é dado a determinados rituais, lugares e suas significações. Assim também, as técnicas e práticas que os indivíduos utilizam para serem mais produtivos ou adaptados ao espaço em que vivem, o modo como imaginam, atualizam e difundem seu saber, assim como os mitos, religiões e ideologias que contribuem para dar sentido à vida e ao contexto onde ela se dá (CLAVAL, 2014).

Esse processo é evidenciado por um dos entrevistados, quando indica algumas ações de resistência para a continuidade de seu principal ritual: 
Nós tem uma ONG ali, nós tem os mesmo roupão que nós usa pra dançar lá na aldeia, é uma tradição que nunca acaba né, os mais velhos vão se acabando e os novos vão tomando conta e não acaba nunca. Tinha uns mais velhos lá na aldeia e tinha uns brancos que não gostavam dizia que essas coisas de índio eram coisas de macumba. E a maioria dos índios não podiam ter filhos e os filhos eram tudo escondidos nas serras e brincava mais à noite, fazia a dança mais à noite, ai quando o branco ia chegando dava o toque e todo mundo se escondia e ficava só o fogo aceso ai eles iam embora, ai começava a festa de novo mas nunca acabou (Adilson Pankararu).

A cultura é transmitida de uma geração à outra através de trocas entre os indivíduos e grupos, levando em conta suas interpretações e motivações. Nesse aspecto, os deslocamentos e migrações contribuem para a disseminação de conhecimentos e técnicas em determinada sociedade. Assim, a diversidade da sociedade, bem como o desenvolvimento de conhecimentos, depende não somente do nível técnico desses grupos como também do meio em que se encontram (CLAVAL, 2014).

O relato a seguir expressa as dificuldades na transmissão da cultura dos Pankararu e de sua interação com não indígenas no espaço urbano:

Sim eu sou bem ativa e nunca deixei de ser por conta da minha mãe, porque como ela reza pro pessoal quando precisa, ela participa dos rituais, então não se perdeu dentro de mim, porque quando você não pratica você fica de lado, outro dia teve um menininho em casa e ele perguntou assim: "Esse Maracá é seu?", eu falei: “É", ele falou: "Você sabe cantar?" "Canta pra mim". Então a mãe dele não sabe cantar, eu também sei que a mãe dele não sabe cantar, então quer dizer que não é todo mundo que passa para o seu filho. O meu filho, ele não gosta, quando eu levo ele é uma briga danada, mas ele sabe que ele é Pankararu, quando a minha filha nasceu ele falou assim pra professora dele: "minha irmã é índia", então ele sabe que pertence a um povo, ele só não gosta muito, quando ele vai, ele fica lá sentado, todo mundo tá lá participando da apresentação, e ele fica lá sentado, então é assim, eu sou bem por dentro ainda da cultura (Clarice Pankararu).

Mesmo tratando-se de ações rotineiras, ordinárias da vida cotidiana, essas reproduzem constantemente a cultura de uma sociedade, sendo certo dizer que a cultura não funciona através dos indivíduos por si só, uma religião ou uma crença política, por exemplo, só sobrevive se as pessoas a praticam. Além disso, as transformações da cultura advêm, sejam elas rápidas ou lentas, no ato da reprodução cultural que, em algum momento, alcançam o nível de reflexão e comunicação (COSGROVE, 2012).

Existe na cultura uma dimensão simbólica constituída pelas realidades e signos criados para descrevê-la e verbalizá-la. Quando repetidos em público, determinados gestos adquirem novos significados, gerando àqueles que os vivenciam um sentimento de comunidade, tornando-se ritualístico. O espaço se torna território à medida que essas ações coletivas se fundem à topografia e arquitetura presentes ou aos monumentos criados para alimentar a memória coletiva (CLAVAL, 2014).

Cosgrove (2012) afirma que o estudo da cultura está intimamente ligado ao poder. O grupo dominante procurará impor sua cultura e experiências do mundo, 
tomando suas suposições como verdadeiras e válidas à toda sociedade. A hegemonia cultural pode ser entendida quando essas suposições culturais dominantes estão inseridas em tal nível que se tornam o senso comum, menos visíveis, porém mantendo o poder através da representação cultural que expressa. Isso ocorre não apenas no âmbito político das classes, mas em termos de gênero, etário e étnico.

Quando referimos sobre as identidades dos povos indígenas, não é incomum que a sociedade e a mídia em geral relevem as inúmeras características e particularidades dessa parcela da população, tendo a noção de que basta ser chamado de "índio" para assumir essas diversas características automaticamente. No entanto, conceituar a identidade indígena vai além do que normalmente é divulgado e vinculado nos meios de comunicação e na cultura em geral.

Conforme Hall (2008), a identidade não deve ser compreendida como algo fixo e imutável e nem como algo estável, em especial no mundo contemporâneo. Devido às intensas mudanças no cenário global relacionadas a políticas sociais e humanitárias em geral, ocorre nos dias atuais uma intensa descentralização hierárquica, seja nos âmbitos sociais ou políticos, e a sociedade se vê constantemente em interação com as novas identidades que são criadas em função dos movimentos de luta, tais como feminismo, movimento negro, ambiental, indígenas entre outros.

À medida que se vive novas experiências, as pessoas carregam resquícios dessas vivências na construção de sua identidade. Isso pode nos colocar frente a um sentimento de instabilidade de nossa identidade já construída. Este fato pôde ser claramente observado durante as entrevistas realizadas com os indígenas do Real Parque. A adaptação com o espaço urbano e com as regras que se estabelecem dentro de um novo contexto, os mantém em um continuo processo de adaptação a esse território, conforme é verificado no relato a seguir:

[...] Assim quando nóis saímos de lá pra cá, tinha vez quando eu ia trabalhar, quando eu chegava dentro de casa tava "ariado", não sabia nem onde que eu estava, por que o lugar indígena é mais remoto e aqui é mais cidade né (Adilson Pankararu).

Segundo Woodward (2000), as identidades podem ser consideradas produtos de um contínuo processo cultural, partindo de um pressuposto de que os indivíduos carregam em si traços de identidades históricas herdadas, e são plenamente capazes de reconstruir tais heranças no mundo contemporâneo, afirmando que as histórias sejam elas contadas por nós, sejam contadas por outros, ou até mesmo as que contamos pra nós, são o que caracteriza o que somos.

Ainda de acordo com o autor, identidade e diferença atuam como tradutoras dos desejos dos grupos sociais, por estarem diretamente ligadas com as relações de poder, ambas traduzem simultaneamente 0 ato de incluir e excluir. A afirmação de identidade está diretamente relacionada a demarcações de fronteiras, ou seja, ao que está dentro e o que está fora, a construção da identidade em relação ao outro.

Entretanto, é importante também destacar como se dão as interações entre os sujeitos e/ou os grupos, pois acabam constituindo novas identidades. As variações relacionais configuram os contextos de interações entre os diversos grupos culturais, o que remete a um perspectivismo, como fundamenta Castro (2004). Importante no contexto de relações dos Pankararu e dos não indígenas em um conjunto habitacional, em relação à cidade e ao território de origem.

Os povos indígenas no Brasil passaram, e ainda passam, por situações e preconceitos marcados pela relação histórica de dominação-sujeição com os não índios. Em se tratando de identidades indígenas, podemos dizer que a sociedade 
ainda rotula, estereotipa e faz seus próprios julgamentos em relação às populações indígenas (BAINES, 2001).

A tentativa em fazer valer seus direitos como indígenas morando nas cidades gera ainda diversos discriminações e preconceitos, passando pela desqualificação e negação em reconhecer sua condição como indígena, ou, quando existe o reconhecimento, esse não se traduz na obtenção e garantia dos direitos correspondentes.

Os Guarani, conforme referido anteriormente, viveram um processo de perda contínua, de expropriação e expulsão, e o processo de luta pela demarcação de suas terras, Mesmo que a terra para eles não tivesse o significado de propriedade, mas o de apropriação e de uso, transformou uma batalha jurídica, mesmo restrito a uma reserva, de luta por seus direitos, em uma forma de manutenção de sua existência e de sua identidade como Guarani (FARIA, 2015).

No caso dos Pankararu, isso se revela nas regras de convívio dentro de um conjunto habitacional e o processo de adaptação dos indígenas e não indígenas, 0 que remete a diferentes perspectivas na construção de um espaço coletivo:

Eu falo que aqui dentro da comunidade é igual pra todo mundo, é claro que tem aquele que se incomoda, por conta do cachimbo que tem uns que fuma e tem gente que não gosta do cheiro, reclama, ou não é todo lugar que faz o ritual pra não incomodar o vizinho ou quando faz, avisa o vizinho de baixo porque aqui é apartamento, então são alguns lugares ou talvez a gente não faça em nossas casas porque existe uma preocupação em não incomodar os outros, sei lá se vai vim alguém bater aqui, mas eu acredito que não vão bater não, pois como eu falei os indígenas vivem aqui já tem muitos anos, então acredito que o pessoal aqui já está acostumado (Clarice Pankararu).

De fato, os não indígenas ainda enxergam o índio vindo para os centros urbanos como uma negação de sua origem e condição como indígena, como se assim ele negasse sua "proteção" garantida por lei. Isso não leva em conta os diversos fatos históricos discriminatórios e opressores que permearam desde a colonização, gerando novos preconceitos e dificuldades ainda não tratados de forma correta pela legislação brasileira (MARTINS, 2014).

Não é por acaso que esses pré-julgamentos acontecem, pois os veículos de comunicação têm importante influência na construção desses estereótipos. Como apontou Amparo (2012), a romantização do índio, sua idealização como habitante das aldeias e florestas, impede que se enxergue a situação do índio contemporâneo e se torna uma barreira na afirmação de sua identidade e diversidade. Essa situação fica evidenciada na fala a seguir:

[...] quando eu cheguei aqui eu tive que passar por esse processo todo, eu sabia que eu era indígena, mas eu não me identificava como indígena em lugar nenhum por conta do preconceito, por ser indígena do Nordeste, por que todo mundo tá querendo aquele índio da Amazônia com a carinha de índio, do olhinho puxado e cabelo liso, então pra não ter que toda vez contar a mesma história, ter que dar uma explicação da onde a gente veio tudo, da onde é a minha origem, então eu não falava que eu era indígena, aí com o passar do tempo eu fui pra escola, fiz o cursinho da "Poli" e entrei na universidade, foi que conheci o resto do pessoal que morava aqui, até porque eu não tinha noção de quantas etnias tinham aqui em São Paulo, eu cheguei 
aqui com 15 anos e só fui ter conhecimento com uns vinte e poucos anos, com 26 anos mais ou menos foi que eu vim a ter conhecimento dos outros povos, aí ali foi que eu me afirmei, em todo lugar que eu chego eu falo, eu sou Pankararu e tudo, mas antes eu não me identificava como indígena (Clarice Pankararu).

Segundo Gallois (2004), a grande mídia contribui para que a população indígena, em busca de exercer atividades realizadas pelos não-índios, seja vista como aquela que perdeu sua identidade, demonstrando que tais atividades são incompatíveis com seu modo de vida, o que dificulta a compreensão da dimensão cultural existente no modo de vida dessas populações. Cohn (2001) aponta também uma imagem do índio ligada apenas à sua importância no passado na formação do território e da cultura nacionais e, na atualidade, tornaram-se invisíveis:

A figura do índio no Brasil e o espaço que ele ocupa na sociedade brasileira têm sido concebidos também de modo mutante. Em um primeiro momento, pensa-se o índio como parte da formação da sociedade brasileira, tratando-o, como importante, no passado, para a constituição da singularidade nacional; o foco está, assim, no índio como nosso antepassado, nas heranças que deles recebemos, seja genética, seja cultural, seja na importância que ele teve para a adaptação do colonizador europeu ao novo meio (COHN, 2001, p. 37).

Conforme Souza (2007), os povos indígenas buscam colocar em evidência o simbolismo do território tradicional através da cultura estabelecida. Nesse sentido, os indígenas moradores da favela do Real Parque estão sempre buscando um modo de manutenção de suas tradições, em meio a adaptação a um espaço urbano marcado pela segregação.

Nakashima (2009) coloca que o ritual do Toré e o culto dos encantados são os principais elementos característicos que compõem a identidade do grupo Pankararu, tanto na aldeia Brejo dos Padres em Pernambuco, quanto na favela do Real Parque. O ritual do Toré, quando realizado na cidade, torna-se um importante aliado na afirmação de sua identidade étnica e resistência dos indígenas frente à sociedade que os silenciou no decorrer de sua história. A criação e manutenção de rituais é atualmente a forma de lutar por seus direitos à terra e às melhores condições de subsistência, nesse sentido, uma reterritorialização.

Contudo, o autor afirma que a identidade Pankararu é frequentemente colocada à prova pela sociedade majoritária, pois boa parte dos indígenas são praticantes do cristianismo, o que se deu em razão da influência marcante de missionários cristãos em terras indígenas no século XVII.

Mas também de adaptação, a exemplo, mais recentemente, da atuação das igrejas neopentecostais na favela faz com que uma parte deles tenha reduzido 0 contato com as suas tradições. Como a fala de uma das entrevistadas, em que expõe esse sincretismo:

Sim, tem um que é pastor, já tem Pastor, Pastora, que só crê em Deus e pronto e acabou, não quer mais saber disso, não quer saber mais de Encantado. Eu vou pra igreja, no dia que o pastor não me quiser lá é só mandar eu ir embora, e ele sabe que eu sou liderança, sabe que eu vou nos eventos que eu ando de cocar, mas se eu ficar só na igreja eu vou esquecer de tudo aquilo que eu aprendi na aldeia e tudo aquilo que eu acho que é verdadeiro que eu sinto, aquela energia. Porque querendo ou não, todos nós temos esse contato com a natureza, toda conexão vem da natureza. Eu sei que Deus existe porque como o 
Adilson falou: "Primeiro Deus e depois os encantados", mas se eu deixar tudo que eu acredito é como eu estar fazendo o apagamento da minha história. (Clarice Pankararu)

De toda forma, como coloca Mauro (2007), os elementos da cultura tradicional dos Pankararu têm favorecido uma maior visibilidade, pois suas iniciativas têm contribuído para que essas manifestações não fiquem apenas como uma forma de apresentação para entretenimento, muito pelo contrário, eles buscam através dessas práticas culturais uma maneira de reivindicar seus direitos como indígena. Como nas palavras de Lígia Pankararu:

Eu vou conhecer sim, não vou ficar aqui dentro da aldeia...porque o Brasil é nosso, nós tem que andar...o Brasil é todo nosso, de nós todos...Nós somos um povo que é misturado todo mundo...todos os povos...as pessoas acham que lugar de índio é no mato, lá na aldeia, lógico que não...(vamos) ensinar um caminho, ensinar para um filho que ele pode ter uma faculdade, que ele pode morar numa cidade, os Pankararu tem muito disso, o que mais tem é Pankararu nesse mundo de Deus, já viu algum lugar que não tenha Pankararu?

Os Pankararu do Real Parque, recolocam a questão do direito à cidade, pois, duplamente discriminados, por serem índios e por serem favelados, revelam a necessidade de mudança da própria concepção de cidade, como afirmou Amparo (2012), em que os índios deveriam fazer parte desta não como sujeitos periféricos, pois por vocação, a cidade deveria ser o lócus da pluralidade política e cultural.

\section{CONSIDERAÇÕES FINAIS}

Passados hoje tantos anos desde a vinda dos primeiros Pankararu para a cidade de São Paulo, a impressão que temos da favela é de convivência pacífica entre moradores indígenas e não indígenas. Porém, ao conversar com os entrevistados, alguns aspectos mais particulares dessa convivência ficam expostos. O senso comum de que o índio é um sujeito da floresta, portando cocar, arco e flecha, perdura mesmo na sociedade que convive com os indígenas há tantas décadas.

Esse fato nos faz entender porque os indígenas demoram a se identificar como tais, especialmente nos centros urbanos, com preocupações acerca do preconceito com esses povos e aumento das dificuldades em conseguir, por exemplo, um emprego para tentar se estabelecer. Os Pankararu, por sua história de miscigenação vivida através dos anos de colonização, têm traços que os confundem e fundem ao nordestino não índio, passando por despercebidos junto à essa população tão miscigenada na cidade de São Paulo.

Nota-se, na favela Real Parque, um constante processo de adaptação ao território. Em conversas com os moradores, através da ONG criada por eles, percebemos, mesmo que seja em um curto momento, os Pankararu se organizam no local para manter sua cultura e garantir seus direitos. $O$ trabalho feito com esforço para manter, por exemplo, a tradição na Dança dos Praiás, realizada atualmente na quadra de uma escola do bairro, mostrando assim, mesmo com dificuldades, o processo de resistência continua acontecendo. As relações identitárias que existem estão intrinsicamente ligadas com os rituais religiosos que são realizados pela comunidade, visto que, além de uma manifestação cultural, exercem a função de estabelecer sua reivindicação política e social para toda a sociedade. 
O povo Pankararu resiste na favela Real Parque, trava uma luta diária para se adaptar ao novo território e, ao mesmo tempo, para não colocar em xeque sua cultura e sua identidade, para além do que foi perdido e o que foi ocultado pelos estigmas da sociedade. Não sem dificuldades, estão inseridos na moderna sociedade sem, no entanto, deixarem de ser índios, fazendo um grande esforço para que sua cultura não seja esquecida, como no exemplo de seus rituais religiosos.

O que sobressai é que o índio na cidade não deixa de ser índio, pelo contrário, quanto mais indígenas em contato com o conhecimento e esclarecimento de seus direitos, mais fortes suas ligações com as origens de seu povo, e na articulação com outros movimentos, manifestam a necessidade de superação de um espaço urbano corporativo e fragmentado.

\section{REFERÊNCIAS BIBLIOGRÁFICAS}

AB'SABER, A. N. Geomorfologia do sítio urbano de São Paulo. Cotia, SP: Editorial Ateliê, 2007.

ALBUQUERQUE, M. A. S. Os Pankararu e o Associativismo Indígena na Cidade de São Paulo. Tellus, Campo Grande, v. 9, n. 16, p. 229-235, jan./jun. 2009.

AMPARO, Sandoval dos Santos.Questão indígena como questão urbana: notas para a construção de uma problemática geográfica. Revista Ensaios de Geografia. Rio de Janeiro, v. 1, n. 2, 2012.

ARRUTI, J. M. A árvore Pankararu: fluxos e metáforas da emergência étnica no sertão do São Francisco. In: OLIVEIRA, J. P. (org.) A Viagem da Volta: etnicidade, política e reelaboração cultural no Nordeste indígena. Rio de Janeiro: Contra Capa, 1999, p. 229-278.

BAINES, S. As chamadas "aldeias urbanas" ou índios na cidade. Revista Brasil Indígena, v. 2, n. 7, p. 15-17, nov./dez. 2001.

BARBOSA, J. L.; SILVA, J. de S. e. As favelas como territórios de reinvenção da cidade. Caderno do desenvolvimento Fluminense, Rio de Janeiro, n. 1, fev. 2013.

BRITO, F. Brasil, final do século: a transição para um novo padrão migratório. In: Encontro Nacional de Estudos Populacionais,Anais...Belo Horizonte: UFMG, 2000, p. $1-25$.

CALDEIRA, Teresa P. R. Cidade de muros: crime, segregação e cidadania em São Paulo. São Paulo: Ed. 34/Edusp, 2000.

CASTRO, Eduardo Viveiros de. Perspectivismo e multinaturalismo naAmérica indígena. Revista O que nos faz pensar, n. 18, Rio de Janeiro, set. 2004.

CLAVAL, P. A geografia cultural, 4 ed., Florianópolis: Editora da UFSC, 2014. 456 p.

COHN, C. Culturas em transformação: os índios e a civilização. São Paulo em Perspectiva, São Paulo, v. 15 n.2, p. 36-42, abr./jun. 2001 
COSGROVE, D. A geografia está em toda parte: cultura e simbolismo nas paisagens humanas. In: CORREAA, R. L.; ROSENDAHL, Z. (org.) Geografia cultural: uma analogia, Rio de Janeiro: EdUERJ, 2012, p. 219 - 238.

D'ANDREA, T. P. Nas tramas da segregação: o real panorama da Polís. Dissertação (Mestrado) - Universidade de São Paulo/Departamento de Sociologia, São Paulo, 2008.

DI GIULIO, G.; VASCONCELLOS, M. Contribuições das Ciências Humanas para o debate sobre mudanças ambientais: um olhar sobre São Paulo. Estudos Avançados, São Paulo, v. 28, n. 82, p. 41-63, 2014.

FARIA, Camilla Salles de. A luta Guarani pela terra na metrópole paulistana: contradições entre a propriedade privada capitalista e a apropriação indígena. Tese (Doutorado), Departamento de Geografia, Universidade de São Paulo, 2015.

GALLOIS, D. T. Terras ocupadas? Territórios? Territorialidades? In: RICARDO, F. P. Terras indígenas e unidades de conservação da natureza. São Paulo: Instituto Socioambiental, 2004.

GOHN, Maria da Glória. Morumbi: o contraditório bairro-região de São Paulo. CADERNO CRH. Salvador, v. 23, n. 59, p. 267-281, Maio/Ago. 2010.

HALL, S. A identidade cultural na pós-modernidade. 9. ed. Rio de Janeiro: DP\&A, 2008.

HAESBAERT, R. Precarização, reclusão e "exclusão" territorial. Terra Livre, Goiânia, v. 2, n. 23, p. 35-52, jul./dez. 2004.

HAESBAERT, R Da desterritorialização à multiterritorialidade. In: X Encontro de Geógrafos da América Latina, 2005. São Paulo. Anais...São Paulo, 2005, p. 6774 6792. Disponível em: www.planificacion.geoamerica.org/textos/haesbaert_multi.pdf. Acesso em: 10 nov. 2018

HAESBAERT, R. O mito da desterritorialização: do "fim dos territórios" à multiterritorialidade. 6.ed. Rio de Janeiro: Bertrand Brasil, 2011. 396 p.

IBGE - INSTITUTO BRASILEIRO DE GEOGRAFIA E ESTATÍSTICA. Censo Demográfico 2010 - Indígenas. Rio de Janeiro: IBGE, 2010.

LANGENBUCH, J. R. A estruturação da Grande São Paulo: Estudo de Geografia Urbana. Tese de doutoramento. Rio Claro: Unesp, 1968.

LIMA, M. S. B.; MOREIRA, E.V. A pesquisa qualitativa em geografia. Caderno Prudentino de Geografia, n.37, v.2, p. 27-55, ago./dez. 2015.

MARTINS, F. do E. S. "Os Pankararu paulistanos" uma situação de emergência étnico-identitária. Revista Ambivalências. São Paulo, v. 2, n. 4, p. 97 - 123, jul./dez. 2014.

MAURO, V. F. Breves considerações acerca das atuais condições de vida do povo 
Pankararu. Revista de estudos e pesquisas - FUNAI, Brasília, v. 4, n. 1, p. 109 129, jul. 207.

NAKASHIMA, E. Y. Reatando as pontas das ramas: a inserção dos alunos da etnia indígena Pankararu em uma escola pública na cidade de São Paulo. Dissertação (Mestrado - Psicologia e Educação), Faculdade de Educação da Universidade de São Paulo, São Paulo, 2009.

NAKASHIMA, E. Y.; ALBUQUERQUE, M. A. dos S. A cultura política da visibilidade: os Pankararu na cidade de São Paulo. Estudos Históricos, Rio de Janeiro, v. 24, n. 47, p. 182-201, jan./jun. de 2011.'

NASCIMENTO, A. C.; VIEIRA, C. M. N. O índio e o espaço urbano: breves considerações sobre o contexto indígena na cidade. Cordis. História: Cidade, Esporte e Lazer, São Paulo, n. 14, p. 118-136, jan./jun. 2015.

PRADO, T. A. S. Z. do. Reurbanização da favela Real Parque: uma análise sobre possibilidades e impactos da reestruturação urbana para a localidade. Dissertação (Mestrado) - Universidade de São Paulo/ Faculdade de Saúde Pública, São Paulo, 2017.

REZENDE, H. D. de. Forma. Reforma. Desforma: o novo formato da política pública para favelas. 2015. Dissertação (Mestrado) - Universidade de São Paulo/Faculdade de Aquitetura e Urbanismo, São Paulo, 2015.

SAQUET, M. A.; MONDARDO, M. L. A construção de territórios na migração por meios de rede de relações sociais. Revista NERA, Presidente Prudente, v. 11, n. 3, p. 118 -127 , jul./dez. 2008.

SILVA, E. Índios organizados, mobilizados e atuantes: história indígena em Pernambuco nos documentos do Arquivo Público. Revista de Estudos e Pesquisas, FUNAI, Brasília, v.3, n.1/2, p.175-224, jul./dez. 2006.

SOUZA, J. L. de. Da desterritorialização ao território simbólico: o caminho de uma sociedade indígena rumo ao seu território tradicional. Caminhos de Geografia, Uberlândia, v. 8, n. 23, p. $73-80$, out. 2007.

SOUZA, M. L. de. Os conceitos fundamentais da pesquisa sócio-espacial. 2 ed. Rio de Janeiro: Bertrand Brasil, 2015.

WOODWARD, K. Identidade e diferença: uma introdução teórica e conceitual. In: SILVA, T. T. (org). Identidade e diferença: a perspectiva dos estudos culturais. Petrópolis: Vozes, 2000, 133p. 